\title{
Estratégia de Saúde Pública para a Pandemia COVID-19 em Portugal: Contribuições da Experiência Internacional
}

\author{
A Public Health Strategy for the COVID-19 Pandemic in \\ Portugal: Learning from International Experience
}

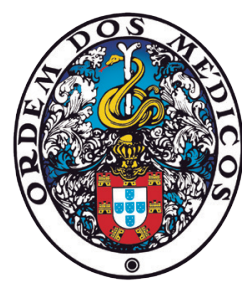

Constantino SAKELLARIDES $\square^{1}$, Fernando ARAÚJO ${ }^{2,3}$

Acta Med Port 2020 Jul-Aug;33(7-8):456-458 - https://doi.org/10.20344/amp.14130

Palavras-chave: COVID-19; Pandemia; Saúde Pública

Keywords: COVID-19; Pandemics; Public Health

As respostas ao atual desafio pandémico têm evoluído com a progressão global deste fenómeno, com os conhecimentos que esta evolução tem proporcionado e com as diferentes abordagens que os países têm adotado para gerir esta situação. Ao analisar a experiência já acumulada, a caminho do primeiro semestre desta pandemia, parece útil considerar duas fases distintas na sua evolução: a primeira, que culminou com a adoção de medidas de confinamento generalizado; a segunda, a do pós-confinamento, em que a necessidade de uma estratégia de Saúde Pública para o país, fundamentada, integrada e explícita, parece agora mais evidente.

\section{Contenção, supressão da transmissão e confinamento}

A 23 de janeiro, a Organização Mundial de Saúde (OMS) convoca o Comité de Emergência, ao abrigo do Regulamento Sanitário Internacional (2005)': face às notícias que vêm da China, deve ou não a OMS declarar uma emergência de Saúde Pública? Dadas as eventuais implicações internacionais dessa declaração o Comité hesita durante praticamente uma semana, até que finalmente decide a favor, permitindo a declaração de emergência pelo Diretor-Geral da OMS a 31 de janeiro. ${ }^{2-4}$

A expansão da epidemia no norte de Itália, na segunda metade de fevereiro, leva progressivamente ao agravamento da situação no ocidente europeu (particularmente França e Espanha). Isso torna-se evidente na segunda semana de março, quando a OMS, a 11 desse mês, declara a situação de pandemia. ${ }^{5}$ Nesse período, em termos de conhecimento científico e decisão política, a situação é particularmente confusa: o modelo de reposta à pandemia ainda é o herdado das gripes pandémicas (contenção seguida de mitigação) mas existem já razões para supor que o coronavírus responsável por esta pandemia requer outro tipo de resposta, sem, no entanto, esta se ter ainda configurado.

Só a 16 de Março, com a publicação do trabalho de Neil Ferguson e colaboradores da equipe do Imperial College de Londres, ${ }^{6}$ emerge um modelo de resposta pandémica

alternativo ao da gripe: em vez de mitigar, é preciso suprimir a transmissão do vírus. Afastamo-nos do modelo da gripe e aproximamo-nos da abordagem ao Ébola. E este requer medidas de distanciamento radicais - o confinamento.

Fase de pós confinamento: a necessidade de uma estratégia de Saúde Pública

A fase de pós-confinamento, que começou a observar-se em diversos países entre fins de abril e início de maio, está associada à evolução da curva epidémica (com um rácio de transmissibilidade inferior a 1) e às múltiplas pressões para iniciar a 'normalização' da vida económica e social.

A Organização Mundial da Saúde ${ }^{7}$ e, na Europa, a Comissão Europeia, ${ }^{8}$ emitiram orientações para esta fase de pós-confinamento, e diferentes países procuraram adaptá-las às suas circunstâncias particulares. Entre as várias abordagens internacionais disponíveis, uma que merece particular atenção é aquela que foi adotada pela Nova Zelândia. $E$ isso porque é aquela que mais se aproxima de uma estratégia de Saúde Pública fundamentada, integrada e explícita.

A abordagem da Nova Zelândia centra-se na definição de quatro níveis de alerta que descrevem as medidas sociais e de saúde pública adotadas neste país, como resposta à pandemia em curso, em função da situação epidemiológica observada (Fig. 1). ${ }^{9}$ As medidas descritas podem ser alteradas de acordo com a evolução do conhecimento científico e da pandemia, e também da avaliação do impacto das medidas já tomadas no país. É de acentuar que estes níveis de alerta se aplicam a nível nacional, mas diferenciam-se também a nível local, de acordo com a situação epidemiológica. Os níveis de alerta podem evoluir em ambos os sentidos (ascendente e descendente).

O sistema de alertas adotado pela Nova Zelândia permite à população do país ter um conhecimento detalhado daquilo que corresponde efetivamente a uma estratégia de Saúde Pública, e se prepare e atue em conformidade.

Considerando a importância das especificidades locais

1. Escola Nacional de Saúde Pública. Universidade NOVA de Lisboa. Lisboa. Portugal.

2. Centro Hospitalar de São João. Porto. Portugal.

3. Faculdade de Medicina. Universidade do Porto. Porto. Portugal.

$\triangle$ Autor correspondente: Constantino Sakellarides. sak@ensp.unl.pt

Recebido: 14 de maio de 2020 - Aceite: 22 de maio de 2020 | Copyright @ Ordem dos Médicos 2020 


\section{COVID-19 na Nova Zelândia: níveis de alerta - resumo}

\begin{tabular}{|c|c|c|}
\hline Níveis de alerta & Avaliação de risco & $\begin{array}{l}\text { Medidas a adotar } \\
\text { (nacionalmente ou localmente) }\end{array}$ \\
\hline $\begin{array}{l}\text { Nivel 4: } \\
\text { Confinamento para conter a doença. }\end{array}$ & $\begin{array}{l}\text { Transmissão na comunidade em curso. Surtos } \\
\text { generalizados e novos clusters. }\end{array}$ & \multirow{4}{*}{$\begin{array}{l}\text { Listagem das medidas em cada } \\
\text { domínio da atividade social, } \\
\text { económica e sanitária, que são } \\
\text { limitadas ou permitidas em cada } \\
\text { nível de alerta. }\end{array}$} \\
\hline $\begin{array}{l}\text { Nível 3: } \\
\text { Restrições necessárias para fazer face ao } \\
\text { alto risco da doença não ser contida. }\end{array}$ & $\begin{array}{l}\text { Transmissão na comunidade pode estar a ocorrer. } \\
\text { Novos clusters podem ocorrer, mas são controláveis } \\
\text { através de testagem e identificação dos contactos. }\end{array}$ & \\
\hline $\begin{array}{l}\text { Nível 2: } \\
\text { A doença está contida, mas mantém-se o } \\
\text { risco de transmissão na comunidade. }\end{array}$ & $\begin{array}{l}\text { Transmissão domíciliaria pode estar a acontecer. } \\
\text { Ocorrem clusters individualizados ou isolados. }\end{array}$ & \\
\hline $\begin{array}{l}\text { Nível 1: } \\
\text { A doença está contida, em alerta para } \\
\text { uma possível reintrodução. }\end{array}$ & $\begin{array}{l}\text { COVID-19 não está controlada internacionalmente. } \\
\text { Casos isolados de transmissão domíciliaria pode } \\
\text { estar a ocorrer no País. }\end{array}$ & \\
\hline
\end{tabular}

Figura 1 - Níveis de alerta da resposta à pandemia COVID-19, na Nova Zelândia. Adaptado do quadro resumo do sistema de alertas na Nova Zelândia. ${ }^{9}$

nos processos epidémicos desta natureza, o governo da Nova Zelândia proporciona à população do país informação contínua e detalhada dos clusters de transmissão ativa no país - localização, número total de casos, número de casos nas últimas 24 horas, número de pessoas recuperadas, origem e estado atual da transmissão.

Como exemplo, no dia 7 de maio, existiam na Nova Zelândia 16 clusters de transmissão da COVID-19: eventos (casamentos e outro tipo de reuniões), lares de idosos, cruzeiros e outros grupos de viagens, escolas e empresas. ${ }^{10}$

Estes são ensinamentos úteis para Portugal: a fase de confinamento caracterizou-se por uma boa resposta das autoridades e da população do país. Durou pouco menos de dois meses. A fase seguinte é consideravelmente mais complexa e também muito mais prolongada. Há que evitar avanços e recuos sem um enquadramento que explicite critérios fundamentados e suas implicações.

A própria terminologia em uso parece desadequada. Não se trata de 'desconfinar' e muito menos de pós-confinamento. Trata-se antes de gerir as transições entre diferentes estadios na saúde pública do país, através de uma estratégia pré-estabelecida para o efeito.

\section{Ensinamentos e implicações para Portugal}

Tendo sido decidido, recentemente, que o país entrou numa fase de 'desconfinamento', é particularmente importante que se adote agora uma estratégia de Saúde Pública para o presente e futuro próximo. Esta deverá ser cientificamente fundamentada, integrando as múltiplas dimensões de uma resposta abrangente à pandemia, explicita e acessível, contando com a participação de todos para a concretização dos resultados esperados.

É particularmente importante explicitar a base científica da estratégia delineada, e dos dispositivos institucionais que lhe deram origem. A transparência, pilar essencial da comunicação de risco, permite maior confiança nas medidas adotadas.

A estratégia de Saúde Pública para Portugal 2020-2021, como resposta à COVID-19, evoluirá para fazer parte, necessariamente, do Plano Nacional de Saúde Pública. ${ }^{10}$ Esta estratégia tem como principais objetivos proporcionar uma visão de conjunto da situação de saúde e uma ação integrada na resposta ao desafio da COVID-19, incluindo: a determinação dos perfis epidemiológicos associados à infeção, a nível nacional, regional e local, as medidas que correspondem a um determinado patamar de risco, os efeitos dessas medidas na saúde individual e coletiva e a forma de minimizar esses efeitos e, finalmente, aquilo que se faz para suscitar comportamentos informados das pessoas face a estes desafios. Poderá conter os seguintes elementos:

1. Perfis ou patamares epidemiológicos de referência (correspondentes aos níveis de alerta da estratégia da Nova Zelândia) que incluam informação detalhada sobre as tipologias da transmissão em causa, assim como a identificação das medidas económicas, sociais e sanitárias que correspondem a esse perfil epidemiológico e dos critérios que gerem as transições entre patamares diferentes;

2. Nível nacional, regional e local: acesso detalhado e contínuo da informação relevante a nível nacional, regional e local. Esta inclui também as estratégias de testagem e de avaliação serológica relativa à incidência da infeção, informação comportamental (mobilidade, distanciamento e proteção individual) e conhecimento sobre o acesso e as respostas dos serviços de saúde locais. A identificação dos 'pontos quentes' locais é de importância crítica. As estratégias regionais e locais enquadram-se nas orientações gerais da estratégia nacional.

3. Promoção e proteção da saúde, de grupos populacionais específicos: explicitação das ações de promoção e proteção de saúde, física e mental, necessárias desde a infância (os desafios do desenvolvimento infantil), à escola (o papel da socialização escolar), ao trabalho (da organização do trabalho e a proteção dos desempregados) até ao processo de envelhecimento (do envelhecimento ativo à morbilidade múltipla);

4. Determinantes sociais da saúde: particular atenção aos efeitos do aumento das desigualdades sociais e do 
agravamento da pobreza e do desemprego. Neste contexto importa assumir uma perspetiva de curto, médio e longo prazo;

5. Comunidades inteligentes: envolvimento das pessoas na sua estratégia de saúde pública, evitando tanto os excessos do isolamento como a negligência da fadiga pandémica, promovendo 'comunidades inteligentes' através de uma gestão da informação e do conhecimento que conduza a uma efetiva inteligência colaborativa;

6. Resposta do Serviço Nacional de Saúde (SNS): que integre simultaneamente os resultados da aprendizagem dos últimos meses e o início das transformações necessárias para fazer face aos desafios da atualidade e do futuro - que constituam efetivamente um 'regresso ao futuro';

7. Saúde Pública, políticas e orçamentos de bem-estar: articular a estratégia de saúde pública com o conjunto da sociedade, com a economia e com uma nova lógica de estratégia orçamental.

Esta estratégia é também uma oportunidade para articular melhor setores e atores sociais relevantes, cuja ne- cessidade já foi patente no decurso desta pandemia: as autarquias locais, no reforço da sua colaboração com as instituições de saúde; o setor social, nomeadamente as Misericórdias e IPSS, pela sua ação junto das populações mais vulneráveis e os institucionalizados, incluindo os mais idosos; as organizações não governamentais, da ação social à cultura e ao entretenimento, já com iniciativas inovadoras em curso; entidades públicas e privadas associadas às questões do trabalho e do turismo; a comunicação social pelo seu papel essencial na partilha de informação credível e oportuna.

Esta abordagem implicaria também um ainda maior e mais prolongado estreitamento da colaboração entre os diferentes setores da governação e destes com a Academia e as organizações profissionais. E também uma urgente atualização das condições de exercício profissional na saúde, sem esquecer, mais uma vez, os serviços de Saúde Pública.

É importante que uma primeira versão desta estratégia seja adotada a muito curto prazo, sendo posteriormente desenvolvida e aperfeiçoada de acordo com a experiência nacional e internacional disponível.

\section{REFERÊNCIAS}

1. World Health Organization. International Health Regulations (2005). $3^{\text {rd }}$ ed. Geneva: WHO; 2005. [consultado 2020 maio 07]. Disponível em: http://www.who.int/ihr/publications/9789241596664/ en/.

2. World Health Organization Emergency Committee. Statement on the second meeting of the International Health Regulations (2005) Emergency Committee regarding the outbreak of novel coronavirus (2019-nCoV). Geneva: WHO; 30 January 2020. [consultado 2020 maio 07]. Disponível em: https://www.who.int/ news-room/detail/3001-2020-statement-on-the-second-meeting-of-the-international-healthregulations-(2005)-emergency-committee-regarding-the-outbreak-ofnovel- coronavirus-(2019-ncov).

3. World Health Organization. WHO Director-General's statement on IHR Emergency Committee on Novel Coronavirus (2019-nCoV). Geneva: WHO; 2020. [consultado 2020 mai 07]. Disponível em: https:// www. who.int/dg/speeches/detail/who-director-general-s- statement-on-ihremergency-committee-on-novel-coronavirus- (2019-ncov).

4. World Health Organization. Margaret Harris on GPS - Fareed Zakaria, April 12, 2020. [consultado 2020 abr 15]. Disponível em: https://edition. cnn.com/videos/tv/2020/04/12/exp-gps-0412-harris-on-who-responeto-covid-19.cnn.

5. World Health Organization. WHO Director-General's opening remarks at the media briefing on COVID-19 - 11 March 2020. [consultado 2020 mar 12]. Disponível em https://www.who.int/dg/speeches/detail/whodirector-general-s-opening-remarks-at-the-media-briefing-on-covid-19--11-march-2020.

6. Ferguson NM, Laydon D, Nedjati-Gilani G, Imai N, Ainslie K, Baguelin $M$, et al. Impact of non-pharmaceutical interventions (NPIs) to reduce COVID-19 mortality and healthcare demand. London: Imperial College COVID-19 Response Team. March 16, 2020. [consultado 2020 mar 22]. Disponível em: (https://www.imperial.ac.uk/ media/imperial-college/ medicine/sph/ide/ gida-fellowships/Imperial-College -COVID19-NPImodelling-16-03-2020.pdf).

7. World Health Organization. WHO Director-General's opening remarks at the media briefing on COVID-19 - 13 April 2020. [consultado 2020 abr 14]. Disponível em: https://www.who.int/dg/speeches/detail/whodirector-general-s-opening-remarks-at-the-media-briefing-on-covid-19-13-april-2020.

8. European Commission. A European roadmap to lifting coronavirus containment measures. 14 April, 20202. [consultado 2020 abr 15]. Disponível em: https://ec.europa.eu/info/live-work-travel-eu/ health/coronavirus-response/european-roadmap-lifting-coronaviruscontainment-measures_en.

9. Government of New Zealand. Unite against COVID19. Alert Systems. [consultado 2020 mai 07]. Disponível em: https://covid19.govt.nz/alertsystem/.

10. Government of New Zealand. Unite against COVID19. Current situation/ significant clusters. [consultado 2020 mai 07]. Disponível em: https:// covid19.govt.nz/latest-updates/.

11. Ministério da Saúde. Plano Nacional de Saúde. Revisão e Extensão a 2020. Lisboa: MS; 2015. 